\title{
GEORGE DAVID BIRKHOFF 1884-1944
}

"Creative intellect is the finest flower of the race. It is by such,- and they are rare-, that the direction of our cultural evolution is determined. It is such as they who set our finest standards and who by their example inspire and hearten others in their striving for what always lies ahead,- - renewed and ever greater accomplishments."

George David Birkhoff was a truly creative mathematical intellect. Where he set his hand to the plow, the furrow never failed to be deepened, if, indeed, its direction was not soon materially altéred. His genius guided him in the divining of many ways to significant and previously inaccessible results-ways in which others have been content to follow him.

Professor Birkhoff was born in the State of Michigan on March 21, 1884. He had his early schooling in the City of Chicago, at the Lewis Institute (now a part of the Illinois Institute of Technology) and at the University of Chicago. For his later college studies he transferred to Harvard, and there he also did his earlier graduate work, taking his bachelor's and master's degrees in 1905 and 1906. His doctorate of philosophy, for which he returned to the University of Chicago, was conferred upon him in 1907. The list of universities at which he functioned then as a regular teacher is not long. From 1907 to 1909 he was an instructor at Wisconsin. From 1909 to 1912 he filled preceptorial and professorial positions at Princeton, and from then on to the time of his death he held professorial chairs at Harvard. As a lecturer or as a visiting faculty member, however, he filled places throughout the years at many institutions in this country and abroad. He died suddenly in his sixty-first year at his home in Cambridge, Massachusetts.

Professor Birkhoff's was a versatile mind. The American mathematicians under whose scientific and personal influence he seems to have especially fallen were Bôcher of Harvard, E. H. Moore of Chicago, and E. B. Van Vleck of Wisconsin. Most of all, however, he was intellectually a disciple of Poincaré. His mathematical publications began in 1904, while he was still an undergraduate, and continued throughout his life. They total roughly to about one hundred memoirs, and form a very substantial contribution to mathematics. With his doctoral work he began an important series of researches in the field of differential equations from which sprung important results in the theories of asymptotic solutions, of boundary value problems, of regular and irregular singular points, and of others. The field of dynamics occupied him throughout his life, and rewarded him with notable discoveries in the theories of stability, the problem of three bodies, Poincaré's geometric theorem, dynamical systems, and in ergodic theory. Over a course of years he 
made important advances in the theory of both linear and $q$-type difference equations, and from the year 1922 on he wrote and lectured considerably upon the theory of relativity. Other fields to which he contributed by publication include those of map coloring, mean-value relations, elasticity, the calculus of variations, modern physical theory, and aesthetic measure.

The profundity of Professor Birkhoff's work was universally recognized abroad as well as at home. In 1918 his researches in dynamics and differential equations were crowned by the Querini-Stampalia prize of the Royal Institute of Science, Arts and Letters, of Venice. In 1923 the American Mathematical Society awarded him its Bôcher prize, and in 1926 he was awarded the annual prize by the American Association for the Advancement of Science. In 1927 he gave by invitation the Society's Colloquium Lectures, and in 1933 he received the prize of the Pontifical Academy of Sciences. He was a member of the National Academy of Sciences, the American Academy of Arts and Sciences, and the American Philosophical Society. He was an "Officier de Legion d'honneur," and a corresponding or honorary member of many European and Latin American scientific organizations. He was president of the American Mathematical Society in 1925, and President of the American Association for the Advancement of Science in 1937. Honorary doctorates had been conferred upon him by Harvard, Brown and the Illinois Institute of Technology, and by the Universities of Chicago, Wisconsin, Pennsylvania, Poitiers, Paris, Athens, Sophia, Lima, Santiago, Buenos Aires, and St. Andrews.

Professor Birkhoff's research papers are to be found in the mathematical journals of many countries, from the years 1904 to 1944 . As books he published the following: Relativity and modern physics (1923); The origin, nature and influence of relativity (1925); Dynamical systems (1927); Aesthetic measure (1933).

R. E. LANGER 